\title{
Portable fixed dynamometry: towards remote muscle strength measurements in patients with motor neuron disease
}

\author{
Jaap N. E. Bakers ${ }^{1,2,3} \cdot$ Leonard H. van den Berg ${ }^{1} \cdot$ Toju G. Ajeks $^{1} \cdot$ Maxine J. Holleman ${ }^{1} \cdot$ Jill Verhoeven ${ }^{1}$. \\ Anita Beelen ${ }^{2,3}$. Johanna M. A. Visser-Meily ${ }^{2,3} \cdot$ Ruben P. A. van Eijk ${ }^{1,4}$
}

Received: 24 September 2020 / Revised: 8 December 2020 / Accepted: 9 December 2020 / Published online: 23 December 2020

(c) The Author(s) 2020

\begin{abstract}
Background We aimed to determine (1) the test-retest reliability of a newly developed portable fixed dynamometer (PFD) as compared to the hand-held dynamometer (HHD) in patients with motor neuron disease (MND) and (2) the PFD's ability to reduce possible examiner-induced ceiling effects.

Methods Test-retest reliability of isometric muscle strength of the quadriceps was measured in patients with MND and non-neurological controls using the HHD and PFD. Reliability was estimated by the intraclass correlation coefficient (ICC) and standard error of measurement (SEM) using linear mixed effects models, and the Bland-Altman method of agreement. Results In total, 45 patients with MND and 43 healthy controls were enrolled in this study. The ICC of the PFD was excellent and similar in both patients and controls (ICC Patients $_{9} 99.5 \%$ vs. ICC $_{\text {Controls }} 98.6 \%$ ) with a SEM of $6.2 \%$. A strong examinerinduced ceiling effect in HHD was found when the participant's strength exceeded that of examiner. Employing the PFD increased the range of muscle strength measurements across individuals nearly twofold from 414 to $783 \mathrm{~N}$.

Conclusions Portable fixed dynamometry may significantly reduce examiner-induced ceiling effects, optimize the standardization of muscle strength testing, and maximize reliability. Ultimately, PFD may improve the delivery of care due to its potential for unsupervised, home-based assessments and reduce the burden to the patient of participating in clinical trials for MND or other neuromuscular diseases.
\end{abstract}

Keywords Fixed dynamometry $\cdot$ Motor neuron disease $\cdot$ Muscle strength $\cdot$ Remote monitoring $\cdot$ Reliability study

\section{Introduction}

Ruben P. A. van Eijk

r.p.a.vaneijk-2@umcutrecht.nl

1 Department of Neurology, UMC Utrecht Brain Centre, University Medical Centre Utrecht, Heidelberglaan 100, 3584 CX Utrecht, The Netherlands

2 Centre of Excellence for Rehabilitation Medicine, UMC Utrecht Brain Centre, University Medical Centre Utrecht, and De Hoogstraat Rehabilitation, Utrecht, The Netherlands

3 Department of Rehabilitation, Physical Therapy Science and Sports, UMC Utrecht Brain Centre, University Medical Centre Utrecht, Utrecht, The Netherlands

4 Biostatistics and Research Support, Julius Centre for Health Sciences and Primary Care, University Medical Centre Utrecht, Utrecht, The Netherlands
Progressive muscle weakness is the hallmark of motor neuron disease (MND) [1]. Muscle strength testing has, therefore, a central role in monitoring MND progression [2-4]. Isometric muscle strength testing using the Hand-Held Dynamometer (HHD) is preferred to the Medical Research Council (MRC) scale due to its increased objectivity and sensitivity [3, 5-7]. Despite its user-friendliness, portability and cost-effectiveness, the HHD's reliability depends on the technique and strength of the examiner [8-13]. These limitations become especially apparent in strong muscle groups such as the quadriceps, resulting in possible ceiling effects and a reduced sensitivity for quantifying MND progression in early disease stages $[14,15]$.

Reducing examiner variability may, therefore, significantly reduce measurement error and optimize the sensitivity of muscle strength testing in MND. Fixed dynamometry (i.e., fixation of the dynamometer in a rigid structure) has 
been shown to alleviate the limitations of the HHD, but currently available systems still require a trained examiner and hospital visits [16-24].

Given the current transition to home-based assessments (i.e., remote monitoring) [25, 26], and the accompanying need for reliable and unsupervised measurements of disease progression [27, 28], we developed a portable fixed dynamometer (PFD). The PFD was developed to evaluate quadriceps strength, because, although there is a gradual rate of decline, the function of this muscle is preserved for a relatively long time, and may provide large effect sizes to quantify muscle strength loss over time in patients with MND [29, 30]. The quadriceps is, therefore, potentially a sensitive muscle group for objective measurement of disease progression in MND. However, as the quadriceps is one of the strongest muscles of the human body, its assessment is challenging, which leads to high variability among examiners when using the HHD [31].

In this study, we aimed to determine (1) the reliability of PFD as compared to the HHD and (2) the PFD's ability to reduce possible examiner-induced ceiling effects.

\section{Methods}

\section{Study population}

Study participants consisted of two groups: (1) participants with a diagnosis within the motor neuron disease spectrum (i.e., Amyotrophic Lateral Sclerosis, Progressive Muscular Atrophy or Primary Lateral Sclerosis) [32], and (2) controls without a neurological condition. Participants were excluded from the study if they met one of the following criteria: (1) less than MRC 2 quadriceps strength in both legs, (2) recent or current pain in knee joint or quadriceps muscle, (3) not able to follow test instructions from the examiner, or (4) having another non-MND disorder that affects muscle strength. All patients with MND were recruited from the outpatient clinic of the University Medical Centre Utrecht, The Netherlands. Control participants were recruited from personnel and students from the department of rehabilitation and geriatrics. The study was approved by the Medical Ethics Committee of the UMCU (protocol number 18-243). All study participants gave written informed consent to participate in this study.

\section{Procedures and measurement techniques}

Two examiners (T.G.A. and M.J.H) were certified for isometric HHD muscle testing after (1) completing the 'Treatment Research Initiative to Cure ALS' (TRICALS) e-course 'Isometric muscle testing in ALS', and (2) satisfactorily completing supervised HHD testing of five control participants. After the registration of patient information and collection of MND-specific characteristics (e.g., ALS functional rating scale [ALSFRS-R] and respiratory functioning), test re-test reliability was assessed in two separate trials on the same day (Fig. 1). Thirty minutes before each trial, participants were requested to refrain from engaging in any strenuous activities. Each trial consisted of six measurements per leg, three with the HHD and three with the PFD. Participants were seated on a chair with back support, hips and knees were kept at 90 degrees. To rule out the influence of arm function, arms were placed in the lap. The starting sequence of the assessment (HHD or PFD) was randomized to minimize the effect of fatigue. All trials within the same participant were conducted by the same examiner, verbally instructing and motivating the patient.

\section{Hand-held dynamometry}

The HHD (MicroFET 2, HOGGAN Scientific) assessments consisted of three isometric 'break contractions' [33], approximately $10 \mathrm{~s}$ apart. The HHD was placed 1 centimeter proximal to the midline between the malleoli. If necessary, a towel roll was placed under the knee to prevent the foot
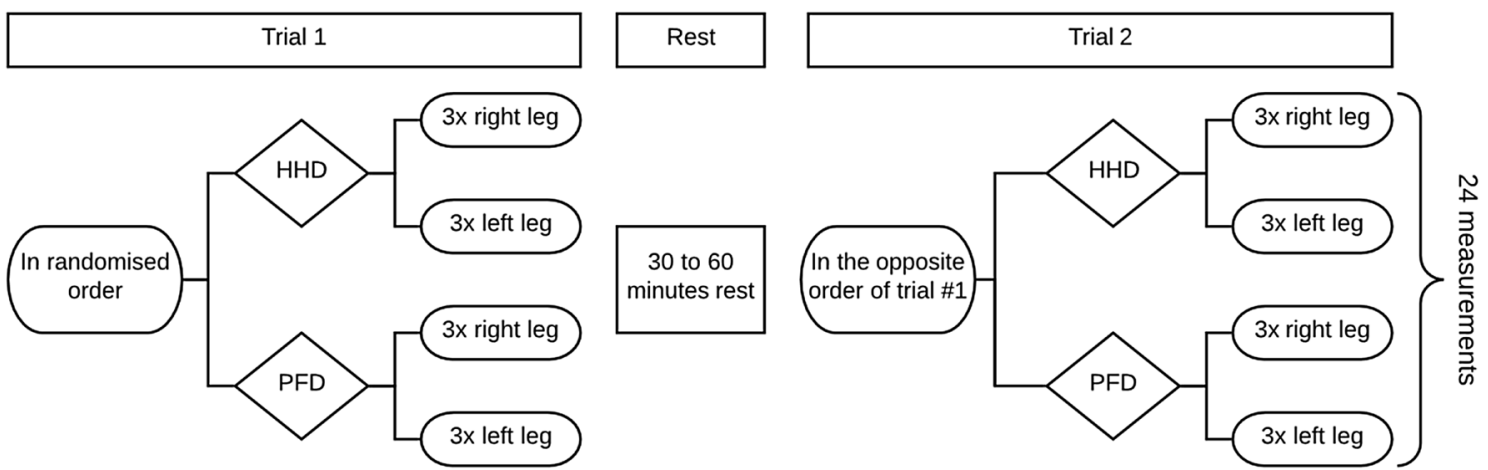

Fig. 1 Overview of study procedures 
from touching the ground. During the maximal contraction, the examiner not only attempted to offer sufficient resistance, but also strived to give a gentile break in the opposite direction of the isometric strength. The score of each measurement, as well as the ability to perform a 'break' (classified as break OR unable-to-break), was registered.

\section{Portable fixed dynamometer}

To be able to measure muscle strength of the quadriceps muscle using a portable, but fixed device, we constructed a simple rigid construction with two HHD holders. In Fig. 2 we illustrate the PFD with the HHDs fixed in a rigid, but portable construction. The PFD can be easily placed in front of a (wheel) chair and standardizes the starting position of the knee joint at 90 degrees. The vertical arm of the PFD (indicated by $a$, Fig. 2) can be adjusted to prevent the feet from touching the ground. The arm length of the PFD (indicated by $b$ ) is adjusted to the length of the participant's lower leg and positions the HHD. We evaluated muscle strength in a fashion identical to that of the HHD. Importantly, in contrast to the HHD, and due to the nature of the fixed construction, the PFD tests consisted of an isometric 'make contraction' as opposed to a 'brake contraction' [33].

\section{Statistical analysis}

Data were summarized using the mean with standard deviation (SD) for continuous variables and number with percentage for categorical variables. Mean differences (MD) were calculated between cases and controls using an independent $t$ test. For each participant, per trial (i.e., trial 1 or 2 ) and per method (i.e., HHD or PFD), we selected the highest muscle
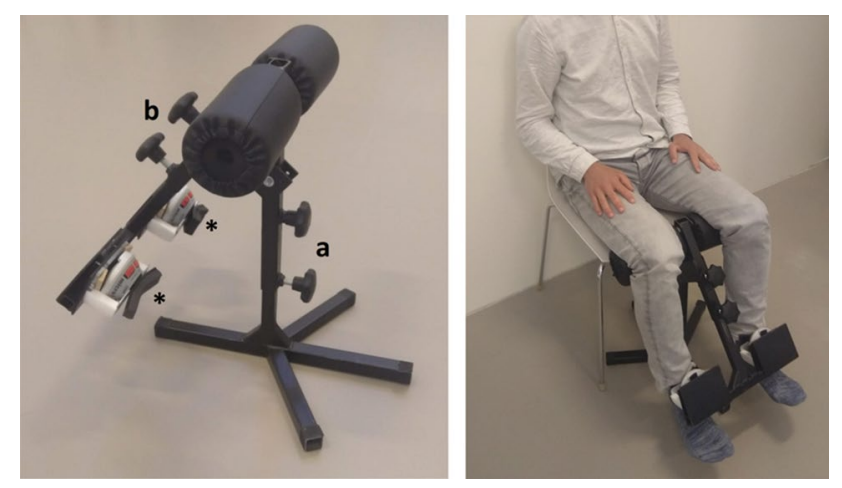

Fig. 2 Prototype of the Portable Fixed Dynamometer. A rigid framework with two holders for the MicroFET dynamometers $(*)$ was created to remove the need for an examiner when evaluating quadriceps strength. With the vertical arm (a), the height was adjusted to prevent the feet from touching the ground. The diagonal arm (b) enabled adjustment of the dynamometer pad to 1 centimeter proximal to the midline between the malleoli strength score from the two values which were most similar of the three measurements taken. Test-retest reliability was assessed using (1) the intraclass correlation coefficient (ICC) and its associated standard error of the measurement (SEM), and (2) the Bland-Altman method of agreement [34, 35]. Due to the heteroscedastic nature of the data, we applied a ${ }^{10} \log$-scale transformation, and calculated the mean difference between trials. The ICC was estimated using a linear mixed effects model, incorporating only a fixed intercept and random intercept per subject. The ICC was then calculated as the percentage of the total variation (i.e., sum of the between-subject and within-subject variation) that can be explained by between-subject differences (i.e., the betweensubject variation); $95 \%$ confidence intervals were obtained by means of bootstrapping $(n=1000)$. The SEM was calculated by taking the square root of the within-subject variation and back-transformed as described elsewhere [35]. Finally, the presence of a ceiling effect was assessed in two steps. First, we assessed the relationship between HHD and PFD measurements with a linear mixed model. This relationship was modelled using a natural spline with four knots. Secondly, we compared the relationship between HHD and PFD measurements with functional loss, using item 8 (walking) of the ALSFRS-R. All analyses were conducted using R. Linear mixed models were fitted and bootstrapped using the lmer and bootMer functions (R package lme4, version 1.1-21), respectively [36].

\section{Results}

Between 4th April 2018 and 8th March 2019, 88 Dutch participants were enrolled in this study: 45 patients with MND and 43 non-neurological controls; their baseline characteristics are presented in Table 1. The age distribution ranged from 22 to 94 years. In the control subjects, the range of muscle strength was larger for PFD ( $8 \mathrm{~N}$ to $783 \mathrm{~N})$ as compared to HHD (15 N to $414 \mathrm{~N})$. As expected, patients with MND had a significantly lower quadriceps strength compared to the control population $(p<0.001)$. The group difference in quadriceps strength (MND vs controls) was, however, considerably larger on PFD $(-113 \mathrm{~N}, 95 \%$ $\mathrm{CI}-52 \mathrm{~N}$ to $-174 \mathrm{~N}$, standardized: 0.792 ) as compared to HHD (- $60 \mathrm{~N}, 95 \%$ CI $23 \mathrm{~N}$ to $97 \mathrm{~N}$, standardized: 0.679).

\section{Reliability HHD and PFD}

In Fig. 3, we provide the measurements of reliability. Due to the heteroscedastic nature of the data, we applied a ${ }^{10} \log$ transformation on the muscle strength scores. For both the HHD and PFD, no systematic differences were found between trials 1 and 2 as indicated by their mean difference (MD, i.e., mean trial $1-$ trial 2). The ICC of the PFD 
Table 1 Baseline characteristics of study population

\begin{tabular}{|c|c|c|}
\hline Characteristic & Patients $(N=45)$ & Controls $(N=43)$ \\
\hline \multicolumn{3}{|l|}{ Age (years) } \\
\hline Median & 62 & 47 \\
\hline Range & $30-84$ & 22-94 \\
\hline Males & $27(60 \%)$ & $22(51 \%)$ \\
\hline Body mass index $\left(\mathrm{kg} / \mathrm{m}^{2}\right)$ & $25(2)$ & $24(3)$ \\
\hline \multicolumn{3}{|l|}{ Muscle strength, average $(N)$} \\
\hline HHD & $216(94)$ & $275(80)$ \\
\hline PFD & $237(126)$ & 350 (159) \\
\hline \multicolumn{3}{|l|}{ Muscle strength, range $(N)$} \\
\hline HHD & $15-373$ & $128-414$ \\
\hline PFD & $8-508$ & $91-783$ \\
\hline \multicolumn{3}{|l|}{ MND subtype } \\
\hline ALS & $41(91 \%)$ & - \\
\hline PMA & $3(7 \%)$ & - \\
\hline PLS & $1(2 \%)$ & - \\
\hline Bulbar onset & $11(24 \%)$ & - \\
\hline FVC, $\%$ predicted-GLI2012 & $78(20)$ & - \\
\hline \multicolumn{3}{|l|}{ Symptom duration (months) } \\
\hline Median & 26 & - \\
\hline Range & $8-311$ & - \\
\hline \multicolumn{3}{|l|}{ Diagnostic delay (months) } \\
\hline Median & 12 & - \\
\hline Range & $3-157$ & - \\
\hline Riluzole use & $37(82 \%)$ & - \\
\hline ALSFRS-R total score (SD) & $35(7)$ & - \\
\hline \multicolumn{3}{|l|}{$\Delta \mathrm{FRS}$ (points per month) } \\
\hline Median & 0.41 & - \\
\hline Range & $0.01-1.94$ & - \\
\hline
\end{tabular}

Data are in mean (SD) or no. (\%). $\Delta \mathrm{FRS}=48-$ ALSFRS-R total score/symptom duration [48]. Prognostic subgroups are based on the ENCALS prediction model [49]

$H H D$ hand-held dynamometry, $P F D$ portable fixed dynamometry, $M N D$ motor neuron disease, $A L S$ amyotrophic lateral sclerosis, $P M A$ progressive muscular atrophy, $P L S$ primary lateral sclerosis, $A L S$ $F R S-R$ revised ALS functional rating scale

was excellent and similar in both patients and controls (ICC Patients $99.5 \%$ vs. ICC Controls $98.6 \%$ ). The back-transformed SEM of the PFD was $6.2 \%$ of the mean strength in Newton, meaning that test-retest values may vary by as much as $\pm 12.5 \%$ of their mean (i.e., approximately two times the SEM) [35]. Interestingly, the ICC of the HHD was excellent, albeit considerably lower in controls (ICC Patients $99.3 \%$ vs. ICC $_{\text {Controls }} 91.8 \%$ ).

\section{Examiner-induced ceiling effects in hand-held dynamometry}

Figure $4 \mathrm{a}$ shows the relationship between HHD and PFD measurements. For lower values up to $200 \mathrm{~N}$, the PFD and
HHD show visually a level of high agreement, resulting in nearly identical strength values. Above 200 to $250 \mathrm{~N}$, the proportion of unable-to-break (Fig. 4b) increases and the correlation between PFD and HHD weakens (as reflected by a deviation from the dashed line). As patients, on average, had lower muscle strength than controls, the correlation coefficient between HHD and PFD was high in patients (Pearson's $r$ 0.94, 95\% CI 0.89 to 0.97), whereas in controls it was considerably lower (Pearson's $r$ controls: $0.71,95 \%$ CI 0.52 to 0.83 ).

When HHD and PFD measurements were compared between subgroups based on the score on question 8 (walking) of the ALSFRS-R (Fig. 5), the effect of the ceiling effect became visible. On a group level, the distinction between scores 2, 3 and 4 of item 8 of the ALSFRS-R, did not appear profound for HHD measurements. However, in PFD measurements, muscle strength was approximately linearly related to the reported functional loss.

\section{Discussion}

In this study, we showed that (1) the PFD achieves a high level of precision with an excellent test-retest reliability over a wide range in muscle strength measurements and (2) the PFD has an advantage over hand-held isometric strength measurements as it reduces examiner-induced ceiling effects. Fixating a dynamometer in a simple and portable framework opens the door to standardized self-assessments by patients in their homes, and may eventually decrease the number of hospital visits and reduce the burden to participate in clinical trials.

Optimizing muscle strength testing is important to optimize the evaluation of efficacy of new MND therapies and to contribute to the delivery of remote care [20]. In the field of voluntary muscle strength testing, the Biodex system is considered to be the gold standard [21, 37, 38]. Similar to the Biodex, other systems have been developed that fixate a loading cell or dynamometer in a rigid framework [e.g., Maximum Voluntary Isometric Contraction (MVIC) or Accurate Test of Limb Isometric Strength (ATLIS)]. The MVIC and ATLIS have proven to be reliable in patients with ALS with an excellent intra-rater test variability ranging from $8.6 \%$ to $8.9 \%$ for the assessment of quadriceps muscle strength.[16, 39] These rigid frameworks are, however, not portable, require visits to the out-patient department, and are still operated by a trained examiner. Other methods that are applied to fixate dynamometers are belt or clamp fixations and stabilization devices [18, 37, 40-44]. Although these have the advantage of being portable and less expensive, unsupervised use has led to inaccurate measurements and patient discomfort [45]. 


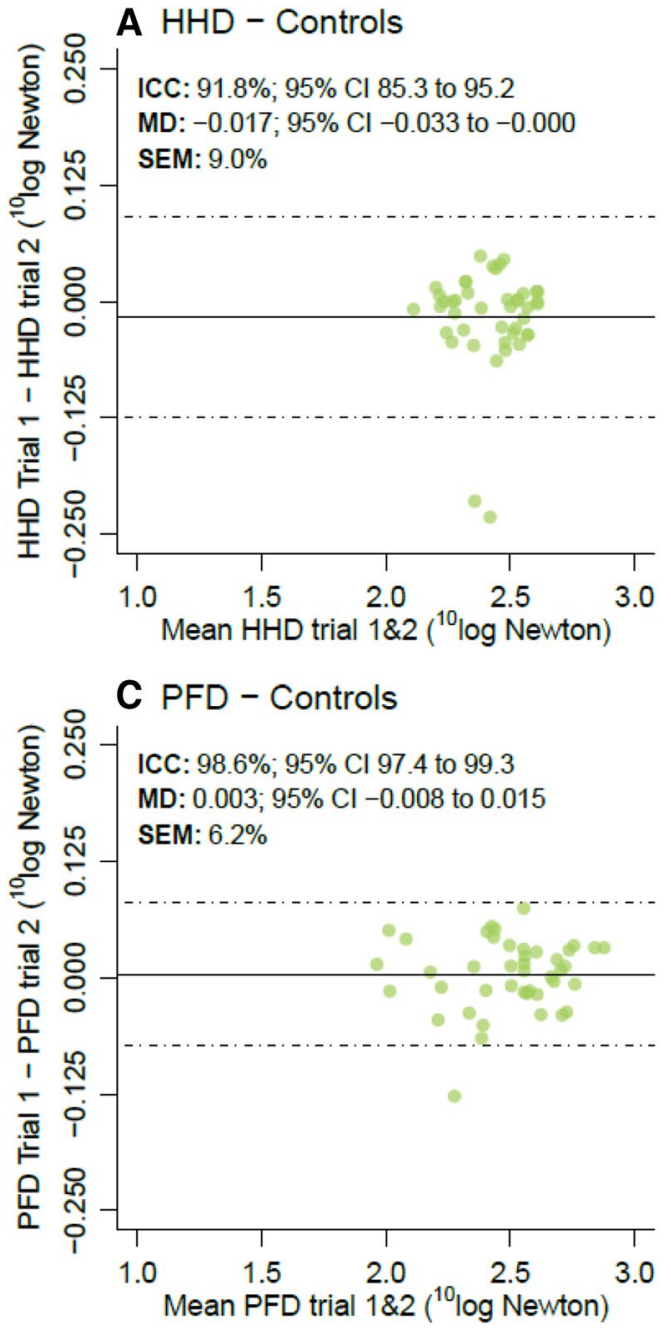

Fig. 3 Bland-Altman plots for test-retest reliability. Bland-Altman plots of the HHD (a-b) and PFD (c-d) for non-neurological controls and patients with MND, respectively. Due to the heteroscedastic nature of the data, we applied a ${ }^{10} \log$-transformation. $M D$ mean dif-

Our results show that the examiner-induced ceiling effect in HHD measurements may be an important source of variability. This is a critical observation as the HHD is a common endpoint in both exploratory and confirmatory clinical trials for ALS [5, 6]. The ceiling effect prevents the investigator from determining the patient's true strength if the examiner is no longer able to overcome the participant's muscle strength $[10,15,21,22]$. This may become particularly problematic in longitudinal settings if patients are assessed by multiple examiners, with each examiner being able to withstand a different amount of force (commonly around 200-300 N) [14, 15]. More importantly, site personnel training and their experience are unlikely to fully eliminate these effects, leading to persistent between-examiner and -site variability. Although the ceiling effects are irrelevant for relatively weak muscle groups, the true strength of major muscle

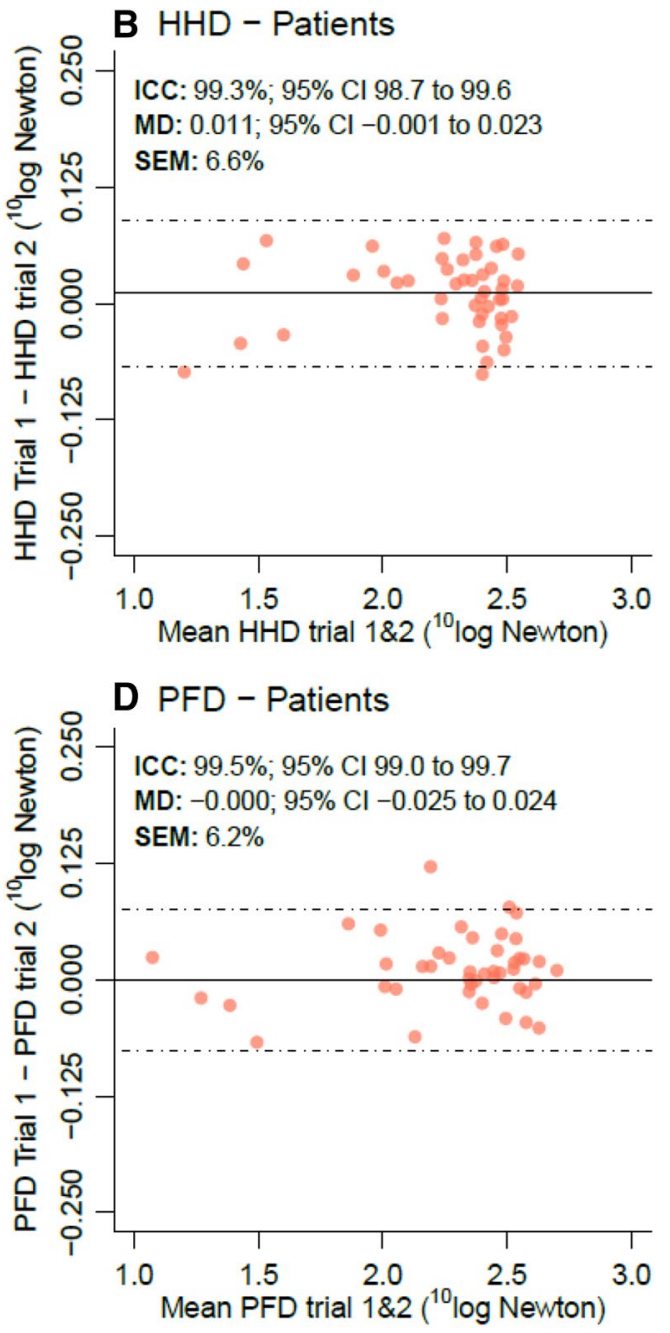

ference between trials 1 and 2, ICC intraclass correlation coefficient, $S E M$ standard error of measurement, expressed as percentage of the mean on the original scale (Newton) [35]

groups like the quadriceps could be significantly underestimated with HHD. Particularly in asymptomatic stages of the disease (as was shown in Fig. 5), this could mean important signals of early disease progression or therapeutic efficacy are missed.

Fixating the HHD in a rigid framework could, therefore, reduce the effect of examiner strength on muscle strength assessments. As is indicated by our results, employing a rigid framework around the HHD increases the range of muscle strength measurements across individuals, especially in early disease. On an individual level, these results are critical as they suggest that the PFD may be able to better track the progression curve of quadriceps strength. On a grouplevel, this may result in larger effect sizes (e.g., standardized group-differences), which could have significant benefits for clinical trials in terms of sample size. Importantly, despite 


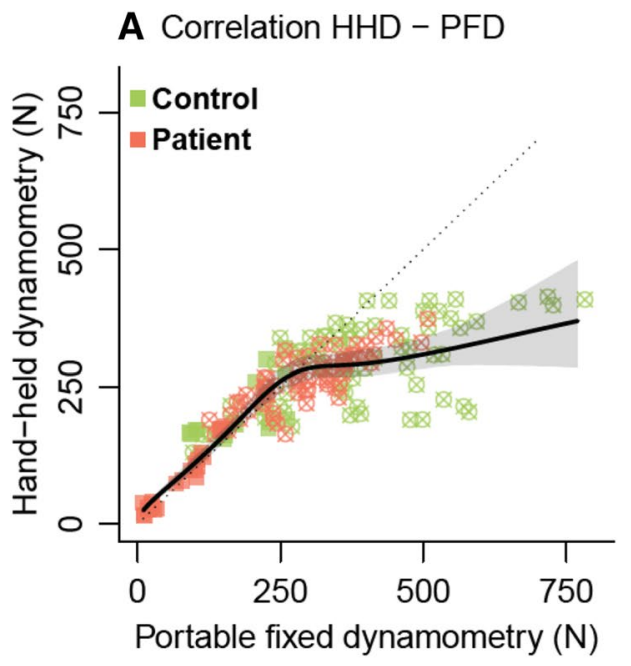

Fig. 4 Association between hand-held and portable fixed dynamometry. a Association between HHD and PFD measurements. The dotted line represents a correlation of 1 (i.e., HHD measurement $=$ PFD measurement and vice-versa). The black solid line represents the observed association, estimated using a linear mixed effects model. The dots with crosses are data points classified as unable-to-break.

\section{B Unable-to-break}

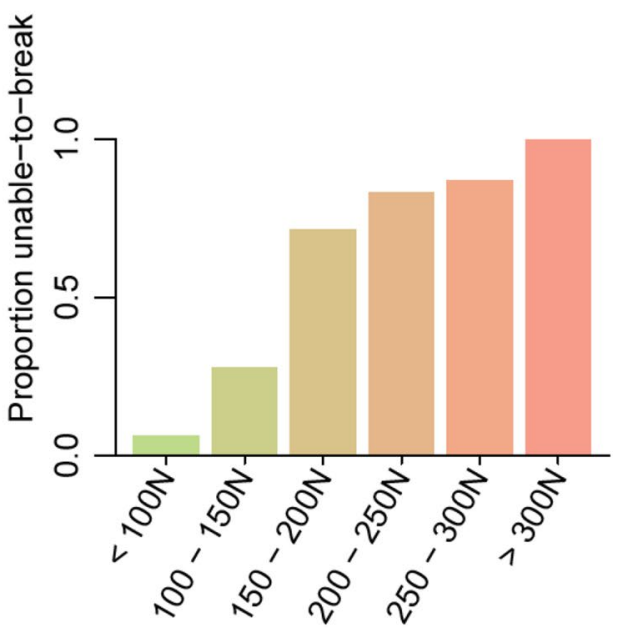

b Muscle strength based on hand-held dynamometry data was categorized and per sub-group we determined the proportion unable-tobreak A clear pattern emerges with the assessor no longer being able to measure the full muscle strength from $300 \mathrm{~N}$ upwards (i.e., a proportion of unable-to-break of 1)
Fig. 5 Relationship between functional loss and muscle strength measurements. Boxplot of the HHD and PFD measurements in 45 patients with MND and 43 non-neurological controls (blue). Functional loss in MND patients was categorized using self-reported function scores of the ALS functional rating scale item 8 (walking); the score range was 0 to 4 , where 0 indicates no leg muscle function (not included) and 4 indicates normal walking function
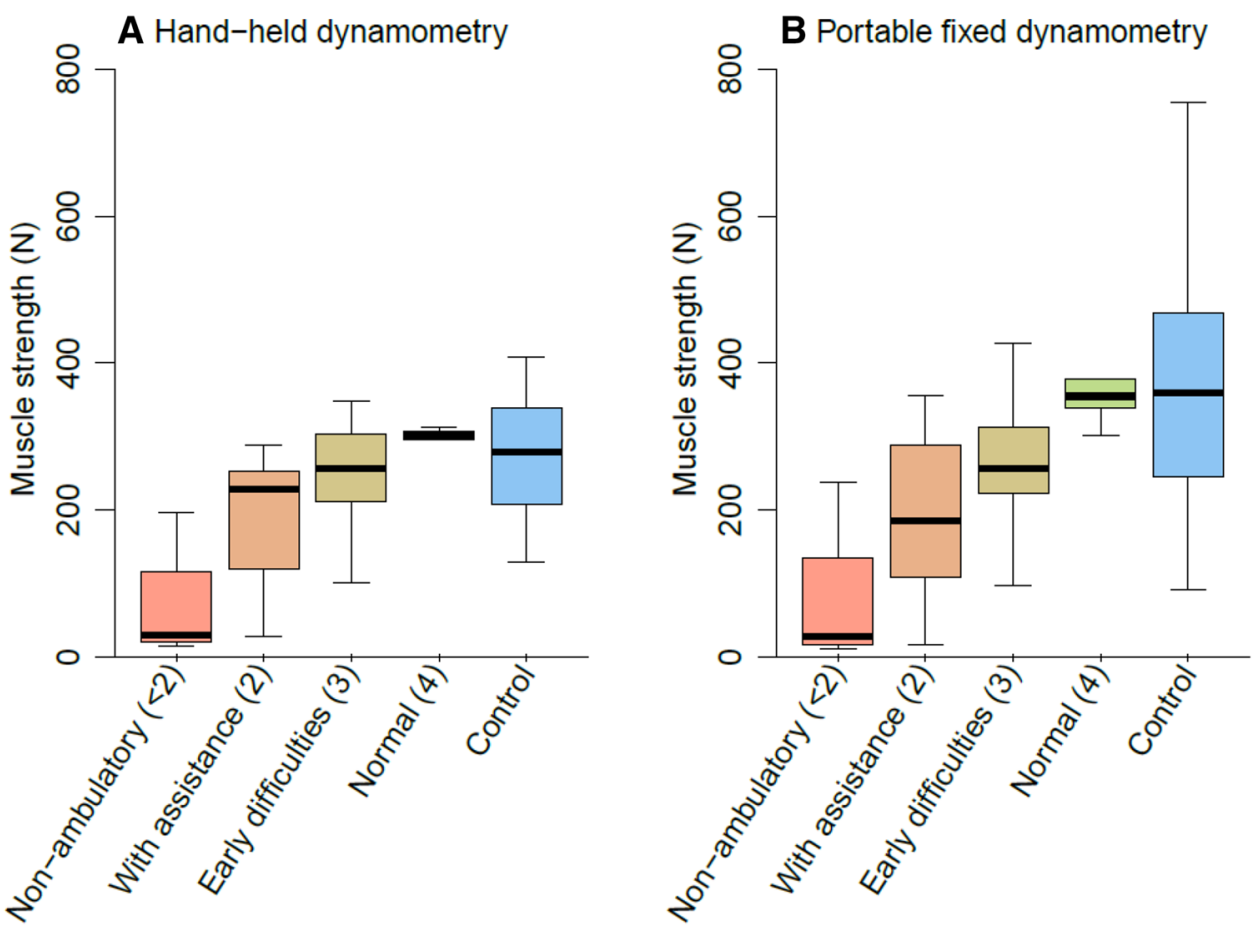

the increase in range, the test-retest reliability of the PFD remained practically unchanged; implementing the PFD may, therefore, help standardize muscle testing protocols in multicenter settings and reduce site-variability.

Our study does, however, have limitations. As the comparison was limited to PFD vs. HHD, it remains to be established how well the PFD performs compared to the gold standard (i.e., Biodex). Previous research indicated a good correlation between HHD and the Biodex for measurements of the quadriceps [21, 46, 47]. Given the strong correlation between HHD and PFD, we expect that the PFD and Biodex will have an equivalent correlation. 
The PFD is currently applied to one muscle group and might, therefore, not capture the full extent of motor function loss in patients with MND (e.g., arm weakness). Extensive muscle strength testing is time-consuming and increases patient burden which may lead to significant attrition over time [2, 45]. It is, therefore, critical to minimize the number of assessments, while obtaining sufficient information for clinical decision-making or monitoring disease progression. Dedicated longitudinal studies are required to use a data-driven approach to determine which muscle groups provide complementary information in addition to quadriceps strength monitoring. An important aspect to consider is the current transition to home-based assessments (i.e., remote monitoring); [23-26] portability, cost-effectiveness and the potential for unsupervised, userfriendly assessments should have a prominent place in any future iteration of the PFD.

In conclusion, our study reveals the value of fixed dynamometry in reducing examiner-induced ceiling effects and optimizing the standardization of muscle strength testing to maximize test-retest reliability. The PFD may improve our ability to track disease progression in individual patients and magnify group-level differences. Ultimately, extending the PFD to home-based settings in MND or other neuromuscular diseases, could improve the delivery of remote care, optimize trial efficiency, and reduce the burden to the patient of participating in clinical trials. A prerequisite for independent remote use is further development of the PFD by integrating the load cells and introducing a patient-friendly user interface.

Acknowledgements This study was funded by the Dutch ALS foundation (Grant: project TryMe).

Author contributions Conceptualization: [JN.E.B], [LH.vdB], [RP.A.vE]; methodology: [RP.A.vE], [AB]; formal analysis and investigation: [JN.E.B], [TG.A] [MJ.H] [JV] [RP.A.vE]; writing—original draft preparation: [JN.E.B]; writing —review and editing: [RP.A.vE], [LH.vdB] [AB] [JM.A.V-M]; funding acquisition: [LH.vdB]; resources: [LH.vdB] [JM.A.V-M] [full name]; supervision: [RP.A.vE].

Funding This work was funded by The Netherlands ALS foundation.

Data availability The corresponding author is able to provide the anonymized data of this study upon reasonable request from qualified investigators.

Code availability The corresponding author is able to provide custom R-studio codes that were used for statistical analysis of this study upon reasonable request from qualified investigators.

\section{Compliance with ethical standards}

Conflicts of interest The authors declare that they have no conflict of interest.
Ethics approval This study was approved by the Medical Ethical Committee of the University Medical Centre Utrecht, Utrecht, The Netherlands (protocol number 18-243).

Consent to participate All subjects provided their consent during trial participation.

Open Access This article is licensed under a Creative Commons Attribution 4.0 International License, which permits use, sharing, adaptation, distribution and reproduction in any medium or format, as long as you give appropriate credit to the original author(s) and the source, provide a link to the Creative Commons licence, and indicate if changes were made. The images or other third party material in this article are included in the article's Creative Commons licence, unless indicated otherwise in a credit line to the material. If material is not included in the article's Creative Commons licence and your intended use is not permitted by statutory regulation or exceeds the permitted use, you will need to obtain permission directly from the copyright holder. To view a copy of this licence, visit http://creativecommons.org/licenses/by/4.0/.

\section{References}

1. National institute for health and care excellence: clinical guidelines; motor neurone disease: assessment and management (2016). In. national institute for health and care excellence: clinical guidelines. The National Institute of Health and Care Excellence (NICE), London. https://www.nice.org.uk/guidance/ng42

2. Cudkowicz M, Qureshi M, Shefner J (2004) Measures and markers in amyotrophic lateral sclerosis. NeuroRx 1(2):273-283. https ://doi.org/10.1602/neurorx.1.2.273

3. Paganoni S, Cudkowicz M, Berry JD (2014) Outcome measures in amyotrophic lateral sclerosis clinical trials. Clin Investig (Lond) 4(7):605-618

4. Rutkove SB (2015) Clinical measures of disease progression in amyotrophic lateral sclerosis. Neurotherapeutics 12(2):384-393. https://doi.org/10.1007/s13311-014-0331-9

5. Cudkowicz ME, Titus S, Kearney M, Yu H, Sherman A, Schoenfeld D, Hayden D, Shui A, Brooks B, Conwit R, Felsenstein D, Greenblatt DJ, Keroack M, Kissel JT, Miller R, Rosenfeld J, Rothstein JD, Simpson E, Tolkoff-Rubin N, Zinman L, Shefner JM, Ceftriaxone Study I (2014) Safety and efficacy of ceftriaxone for amyotrophic lateral sclerosis: a multi-stage, randomised, doubleblind, placebo-controlled trial. Lancet Neurol 13(11):1083-1091. https://doi.org/10.1016/S1474-4422(14)70222-4

6. Cudkowicz ME, van den Berg LH, Shefner JM, Mitsumoto H, Mora JS, Ludolph A, Hardiman O, Bozik ME, Ingersoll EW, Archibald D, Meyers AL, Dong Y, Farwell WR, Kerr DA, investigators E (2013) Dexpramipexole versus placebo for patients with amyotrophic lateral sclerosis (EMPOWER): a randomised, double-blind, phase 3 trial. Lancet Neurol 12(11):1059-1067. https://doi.org/10.1016/S1474-4422(13)70221-7

7. Meininger V, Genge A, van den Berg LH, Robberecht W, Ludolph A, Chio A, Kim SH, Leigh PN, Kiernan MC, Shefner JM, Desnuelle C, Morrison KE, Petri S, Boswell D, Temple J, Mohindra R, Davies M, Bullman J, Rees P, Lavrov A, Group NOGS (2017) Safety and efficacy of ozanezumab in patients with amyotrophic lateral sclerosis: a randomised, double-blind, placebocontrolled, phase 2 trial. Lancet Neurol 16(3):208-216. https:// doi.org/10.1016/S1474-4422(16)30399-4

8. Kolber MJ, Cleland JA (2005) Strength testing using hand-held dynamometry. Phys Therapy Rev 10(2):99-112. https://doi. org/10.1179/108331905X55730 
9. Stark T, Walker B, Phillips JK, Fejer R, Beck R (2011) Handheld dynamometry correlation with the gold standard isokinetic dynamometry: a systematic review. PM R J Injury Funct Rehabilit 3(5):472-479. https://doi.org/10.1016/j.pmrj.2010.10.025

10. Keating JL, Matyas TA (1996) The influence of subject and test design on dynamometric measurements of extremity muscles. Phys Ther 76(8):866-889. https://doi.org/10.1093/ptj/76.8.866a

11. Lu TW, Hsu HC, Chang LY, Chen HL (2007) Enhancing the examiner's resisting force improves the reliability of manual muscle strength measurements: comparison of a new device with hand-held dynamometry. J Rehabil Med 39(9):679-684. https:// doi.org/10.2340/16501977-0107

12. Wikholm JB, Bohannon RW (1991) Hand-held dynamometer measurements: tester strength makes a difference. J Orthop Sports Phys Ther 13(4):191-198. https://doi.org/10.2519/jospt .1991.13.4.191

13. Lu TW, Chien HL, Chang LY, Hsu HC (2012) Enhancing the examiner's resisting force improves the validity of manual muscle strength measurements: application to knee extensors and flexors. J Strength Cond Res 26(9):2364-2371. https://doi. org/10.1519/JSC.0b013e31823db080

14. Beck M, Giess R, Wurffel W, Magnus T, Ochs G, Toyka KV (1999) Comparison of maximal voluntary isometric contraction and Drachman's hand-held dynamometry in evaluating patients with amyotrophic lateral sclerosis. Muscle Nerve 22(9): 1265-1270

15. Visser J, Mans E, de Visser M, van den Berg-Vos RM, Franssen H, de Jong JM, van den Berg LH, Wokke JH, de Haan RJ (2003) Comparison of maximal voluntary isometric contraction and hand-held dynamometry in measuring muscle strength of patients with progressive lower motor neuron syndrome. Neuromuscul Disord 13(9):744-750

16. Andres PL, Skerry LM, Munsat TL, Thornell BJ, Szymonifka J, Schoenfeld DA, Cudkowicz ME (2012) Validation of a new strength measurement device for amyotrophic lateral sclerosis clinical trials. Muscle Nerve 45(1):81-85. https://doi. org/10.1002/mus.22253

17. Bui KL, Mathur S, Dechman G, Maltais F, Camp P, Saey D (2019) Fixed handheld dynamometry provides reliable and valid values for quadriceps isometric strength in people with chronic obstructive pulmonary disease: a multicenter study. Phys Ther. https://doi.org/10.1093/ptj/pzz059

18. Kollock RO Jr, Onate JA, Van Lunen B (2010) The reliability of portable fixed dynamometry during hip and knee strength assessments. J Athl Train 45(4):349-356. https://doi. org/10.4085/1062-6050-45.4.349

19. Mentiplay BF, Perraton LG, Bower KJ, Adair B, Pua YH, Williams GP, McGaw R, Clark RA (2015) Assessment of lower limb muscle strength and power using hand-held and fixed dynamometry: a reliability and validity study. PLoS ONE 10(10):e0140822. https://doi.org/10.1371/journal.pone.01408 22

20. Andres PL, Allred MP, Stephens HE, Proffitt Bunnell M, Siener C, Macklin EA, Haines T, English RA, Fetterman KA, Kasarskis EJ, Florence J, Simmons Z, Cudkowicz ME (2017) Fixed dynamometry is more sensitive than vital capacity or ALS rating scale. Muscle Nerve 56(4):710-715. https://doi.org/10.1002/mus.25586

21. Martin HJ, Yule V, Syddall HE, Dennison EM, Cooper C, Aihie Sayer A (2006) Is hand-held dynamometry useful for the measurement of quadriceps strength in older people? A comparison with the gold standard Bodex dynamometry. Gerontology 52(3):154159. https://doi.org/10.1159/000091824

22. Toonstra J, Mattacola CG (2013) Test-retest reliability and validity of isometric knee-flexion and -extension measurement using 3 methods of assessing muscle strength. J Sport Rehabil 22:1. https ://doi.org/10.1123/jsr.2013.TR7
23. Sarabon N, Kozinc Z, Bishop C, Maffiuletti NA (2020) Factors influencing bilateral deficit and inter-limb asymmetry of maximal and explosive strength: motor task, outcome measure and muscle group. Eur J Appl Physiol 120(7):1681-1688. https://doi. org/10.1007/s00421-020-04399-1

24. Sarabon N, Rosker J, Fruhmann H, Burggraf S, Loefler S, Kern H (2013) Reliability of maximal voluntary contraction related parameters measured by a novel portable isometric knee dynamometer. Phys Med Rehabilit Kurortmed 23(01):22-27. https ://doi.org/10.1055/s-0032-1331190

25. Helleman J, Van Eenennaam R, Kruitwagen ET, Kruithof WJ, Slappendel MJ, Van Den Berg LH, Visser-Meily JMA (2020) Beelen A (2020) Telehealth as part of specialized ALS care: feasibility and user experiences with ALS home-monitoring and coaching. Amyotroph Lateral Scler Frontotemporal Degener. https ://doi.org/10.1080/216784211718712

26. Hobson EV, Baird WO, Bradburn M, Cooper C, Mawson S, Quinn A, Shaw PJ, Walsh T, McDermott CJ (2019) Using telehealth in motor neuron disease to increase access to specialist multidisciplinary care: a UK-based pilot and feasibility study. BMJ Open 9(10):e028525. https://doi.org/10.1136/bmjopen-2018-028525

27. Rutkove SB, Qi K, Shelton K, Liss J, Berisha V, Shefner JM (2019) ALS longitudinal studies with frequent data collection at home: study design and baseline data. Amyotroph Lateral Scler Frontotemporal Degener 20(1-2):61-67. https://doi. org/10.1080/21678421.2018.1541095

28. van Eijk RPA, Bakers JNE, Bunte TM, de Fockert AJ, Eijkemans MJC, van den Berg LH (2019) Accelerometry for remote monitoring of physical activity in amyotrophic lateral sclerosis: a longitudinal cohort study. J Neurol 266(10):2387-2395. https://doi. org/10.1007/s00415-019-09427-5

29. Rushton DJ, Andres PL, Allred P, Baloh RH, Svendsen CN (2017) Patients with ALS show highly correlated progression rates in left and right limb muscles. Neurology 89(2):196-206. https://doi. org/10.1212/WNL.0000000000004105

30. Shields RK, Ruhland JL, Ross MA, Saehler MM, Smith KB, Heffner ML (1998) Analysis of health-related quality of life and muscle impairment in individuals with amyotrophic lateral sclerosis using the medical outcome survey and the Tufts Quantitative Neuromuscular Exam. Arch Phys Med Rehabil 79(7):855-862. https://doi.org/10.1016/s0003-9993(98)90370-7

31. Shefner JM, Liu D, Leitner ML, Schoenfeld D, Johns DR, Ferguson T, Cudkowicz M (2016) Quantitative strength testing in ALS clinical trials. Neurology 87(6):617-624. https://doi.org/10.1212/ WNL.0000000000002941

32. van Es MA, Hardiman O, Chio A, Al-Chalabi A, Pasterkamp RJ, Veldink JH, van den Berg LH (2017) Amyotrophic lateral sclerosis. Lancet 390(10107):2084-2098. https://doi.org/10.1016/S0140 $-6736(17) 31287-4$

33. van der Ploeg RJ, Oosterhuis HJ (1991) The "make/break test" as a diagnostic tool in functional weakness. J Neurol Neurosurg Psychiatry 54(3):248-251. https://doi.org/10.1136/jnnp.54.3.248

34. Ludbrook J (2010) Confidence in Altman-Bland plots: a critical review of the method of differences. Clin Exp Pharmacol Physiol 37(2):143-149. https://doi.org/10.1111/j.1440-1681.2009.05288 .x

35. Euser AM, Dekker FW, le Cessie S (2008) A practical approach to Bland-Altman plots and variation coefficients for log transformed variables. J Clin Epidemiol 61(10):978-982. https://doi. org/10.1016/j.jclinepi.2007.11.003

36. Bates D, Mächler M, Bolker B, Walker S (2015) Fitting linear mixed-effects models using lme4. J Stat Softw 67(1):48. https:// doi.org/10.18637/jss.v067.i01

37. Hogrel JY, Benveniste O, Bachasson D (2020) Routine monitoring of isometric knee extension strength in patients with muscle impairments using a new portable device: cross-validation against 
a standard isokinetic dynamometer. Physiol Meas 41(1):015003. https://doi.org/10.1088/1361-6579/ab6b49

38. Roussel MP, Hebert LJ, Duchesne E (2019) Intra-rater reliability and concurrent validity of quantified muscle testing for maximal knee extensors strength in men with myotonic dystrophy type 1 . J Neuromuscul Dis 6(2):233-240. https://doi.org/10.3233/JND190388

39. Andres PL, Hedlund W, Finison L, Conlon T, Felmus M, Munsat TL (1986) Quantitative motor assessment in amyotrophic lateral sclerosis. Neurology 36(7):937-941. https://doi.org/10.1212/ wnl.36.7.937

40. Jackson SM, Cheng MS, Smith AR Jr, Kolber MJ (2017) Intrarater reliability of hand held dynamometry in measuring lower extremity isometric strength using a portable stabilization device. Musculoskelet Sci Pract 27:137-141. https://doi.org/10.1016/j. math.2016.07.010

41. Koblbauer IF, Lambrecht Y, van der Hulst ML, Neeter C, Engelbert RH, Poolman RW, Scholtes VA (2011) Reliability of maximal isometric knee strength testing with modified hand-held dynamometry in patients awaiting total knee arthroplasty: useful in research and individual patient settings? A reliability study. BMC Musculoskelet Disord 12:249. https://doi. org/10.1186/1471-2474-12-249

42. Kolber MJ, Beekhuizen K, Cheng MS, Fiebert IM (2007) The reliability of hand-held dynamometry in measuring isometric strength of the shoulder internal and external rotator musculature using a stabilization device. Physiother Theory Pract 23(2):119-124. https ://doi.org/10.1080/09593980701213032

43. Shin S, Lee K, Song C (2016) Relationship of body composition, knee extensor strength, and standing balance to lumbar bone mineral density in postmenopausal females. J Phys Ther Sci 28(7):2105-2109. https://doi.org/10.1589/jpts.28.2105

44. Thorborg K, Bandholm T, Holmich P (2013) Hip- and kneestrength assessments using a hand-held dynamometer with external belt-fixation are inter-tester reliable. Knee Surg Sports Traumatol Arthrosc 21(3):550-555. https://doi.org/10.1007/s0016 7-012-2115-2

45. Hansen EM, McCartney CN, Sweeney RS, Palimenio MR, Grindstaff TL (2015) Hand-held dynamometer positioning impacts discomfort during quadriceps strength testing: a validity and reliability study. Int J Sports Phys Ther 10(1):62-68

46. Bohannon RW (1990) Hand-held compared with isokinetic dynamometry for measurement of static knee extension torque (parallel reliability of dynamometers). Clin Phys Physiol Meas 11(3):217-222. https://doi.org/10.1088/0143-0815/11/3/004

47. Reed RL, Den Hartog R, Yochum K, Pearlmutter L, Ruttinger AC, Mooradian AD (1993) A comparison of hand-held isometric strength measurement with isokinetic muscle strength measurement in the elderly. J Am Geriatr Soc 41(1):53-56. https://doi. org/10.1111/j.1532-5415.1993.tb05949.x

48. Kimura F, Fujimura C, Ishida S, Nakajima H, Furutama D, Uehara H, Shinoda K, Sugino M, Hanafusa T (2006) Progression rate of ALSFRS-R at time of diagnosis predicts survival time in ALS. Neurology 66(2):265-267. https://doi.org/10.1212/01.wnl.00001 $94316.91908 .8 \mathrm{a}$

49. Westeneng HJ, Debray TPA, Visser AE, van Eijk RPA, Rooney JPK, Calvo A, Martin S, McDermott CJ, Thompson AG, Pinto S, Kobeleva X, Rosenbohm A, Stubendorff B, Sommer H, Middelkoop BM, Dekker AM, van Vugt J, van Rheenen W, Vajda A, Heverin M, Kazoka M, Hollinger H, Gromicho M, Korner S, Ringer TM, Rodiger A, Gunkel A, Shaw CE, Bredenoord AL, van Es MA, Corcia P, Couratier P, Weber M, Grosskreutz J, Ludolph AC, Petri S, de Carvalho M, Van Damme P, Talbot K, Turner MR, Shaw PJ, Al-Chalabi A, Chio A, Hardiman O, Moons KGM, Veldink JH, van den Berg LH (2018) Prognosis for patients with amyotrophic lateral sclerosis: development and validation of a personalised prediction model. Lancet Neurol 17(5):423-433. https://doi.org/10.1016/S1474-4422(18)30089-9 